\title{
NUMERICAL SIMULATION OF FLOW FIELD IN AIR-JET LOOM MAIN NOZZLE
}

\author{
Shanshan He, Yi Qian, Wenliang Xue*, Longdi Cheng \\ Key Laboratory of Textile Science \& Technology, Ministry of Education, Donghua University, Shanghai 201620, China \\ *Corresponding author. Email: xwl@dhu.edu.cn
}

\begin{abstract}
:
To improve airflow injection capacity of the main nozzle and decrease backflow phenomenon, a new main nozzle structure with two throats is designed. Negative pressure value and negative pressure zone length are first proposed evaluating the strength of backflow phenomenon. Commercial computational fluid dynamic (CFD) code "Fluent" is performed to simulate the flow field inside and outside the main nozzle. Exit velocity increases about $10 \mathrm{~m} / \mathrm{s}$ in new main nozzle. Airflow core length of the new main nozzle is $35 \%$ higher than that of commonly used main nozzle. Smaller negative pressure value and shorter negative pressure zone length mean a weaker backflow phenomenon in the new main nozzle. Bigger air drag force indicates stronger weft insertion ability in the new main nozzle.
\end{abstract}

\section{Keywords:}

Weft insertion; main nozzle; throat structure; air-jet loom; numerical simulation

\section{Introduction}

Weft insertion is the core technology of air-jet loom. The performance of air-jet loom is limited by the degree of mastery of weft insertion principle. The weft insertion system consists of three parts: main nozzle, relay nozzles, and profiled reeds. As the first part of accelerating the weft yarn, main nozzle is crucial for enhancing the performance of the air-jet looms.

Many studies have been done to understand the flow characteristics and optimize the geometry of the main nozzle. The unsteady and turbulent characteristics of airflow in the main nozzle were described by Adanur and Mohamed [1], which indicates that the airflow velocity during the weft insertion process is decided by the distance and the time that after the air left the nozzle. Theoretical basic research by Yan et al. [2] built an equation, which solved the velocity distribution of the intermittent jetted airflow. Their results showed that the airflow tended to be steady and led to a conclusion that the main nozzle should be started earlier than weft insertion. This study also laid the theoretical foundation for the hypothesis that airflow for weft insertion is steady flow. For the experimental studies on air-jet looms, there are also several studies all over the world. The structure of the main nozzle was optimized by Mohamed and Salama [3] and Zhu [4] experimentally. Their results showed that the airflow velocity from the main nozzle increases with the decrease in yarn tube and the increase in the air pressure. Besides, the larger the diameter of the main nozzle, the smaller the airflow velocity is. Ishida and Okajima $[5,6]$ measured the static pressure and the influence of supply pressure and discussed about the acceleration tube length, and further calculation showed the air velocity distribution in the main nozzle as well as the influence of the initial pressure and the length of the main nozzle on that. Furthermore, they also made experiments on the axial and radial velocity components.
These studies provided the basic testing methods for main nozzle study. Some draft forces on weft in this region were also tested and calculated by researchers [7].

With the help of the computational fluid dynamic (CFD) technology development, more work has been done in cooperating with simulation. Numerical analysis of flows in the main nozzle was conducted by Oh et al. [8] who analyzed the effect of supply pressure, acceleration tube length, and circular arc radius on the flow field of the main nozzle using the BaldwinLomax algebraic turbulence model. Numerical simulation study of the flow field in the main nozzle was implemented by Kim et al. [9] using $k-e$ model. The flow field in the main nozzle which has an acceleration tube with a small divergent angle was investigated. An unsteady flow analysis was done by Kim et al. [10] to simulate the intermittent flow inside the main nozzle. Many simulations to optimize the design of the main nozzle and explain the flow field were conducted by a research group of Feng [11-15] in Soochow University. In addition, Xue et al. [16] and Wu et al. [17] studied the flow field in the main nozzle by means of numerical simulation. A new main nozzle structure was designed by Chen et al. [18] to decrease the turbulence and backflow during weft insertion.

Previous studies on the flow field of the main nozzle have been confined to investigate the effect of supply pressure and acceleration tube parameters on flow characteristics in the main nozzle. In the present study, a new main nozzle structure with two throats is designed to improve airflow injection capacity and decrease backflow phenomenon in the weft injection region. Negative pressure value and negative pressure zone length are first proposed evaluating the strength of backflow phenomenon. Chen et al. also designed a new main nozzle structure to eliminate the backflow phenomenon, but the new structure is too complicated and expensive to manufacture. 
Commercial CFD code "Fluent" was performed to simulate the flow field inside and outside the main nozzle. Velocity distributions and air drag force of commonly used main nozzle and new main nozzle were compared. Backflow phenomenon in the weft injection region was discussed in detail. Main nozzle jet flow characteristics were tested, and static pressures were collected in the experiment to verify the results of simulation. Simulation results showed that the new main nozzle improves the injection capacity and reduces the backflow phenomenon effectively.

\section{Structure and flow field model}

\subsection{Structure of new main nozzle}

Throat is the annular chamber with the smallest diameter formed by the outer wall of the hollow needle and the inner wall of the cylinder. The flow will change greatly around the throat region due to its small cross-sectional area, which has an important influence on the flow field characteristics.

The structure and schematic diagram of the new main nozzle are shown in Figure 1. The new main nozzle designed in this paper is named as nozzle $B$, and it has two throat structures ( 3 and 4) instead of only one throat structure (4) of nozzle A, which is named as nozzle $A$. It is made up of four main parts: a hollow needle (A), a body (B), a cylinder (C), and an acceleration tube (D), and the internal annular chamber made of them is the actual flow passage. Compressed airflow from inlet (2), come together with the weft sucked in by inlet (1) in injection region (6). The yarn is accelerated by the flow along the acceleration tube (D) and released freely to the atmosphere from outlet (8).

\subsection{Flow field model of new main nozzle}

The structures of the flow field in main nozzle are shown in Figure 2. Nozzle B has two throat structures compared with nozzle A, as shown in Figure 2(b). Throat of nozzle A is located in the joint of the hollow needle tip and the acceleration tube, as shown in Figure 2(a). The first throat of nozzle B is located in the middle of the channel formed by the outer wall of the hollow needle and the inner wall of the cylinder besides the second one in the hollow needle tip, as shown in Figure 2(b).

To analyze the flow field in the main nozzle, we divided it into four regions.

Region A (sections 0-5): airflow in nozzle A diverges twice, but airflow in nozzle $B$ diverges thrice. Nozzle $B$ allows one more divergence than nozzle $A$ in sections $3-4$, which means one more chance to accelerate.

Region B (sections 5-6): airflow channel cross-section increases sharply from sections 5 to 6 and a negative pressure zone appeared in region $\mathrm{B}$. Backflow phenomenon also appears in this region. Weft yarns are sucked in by the negative pressure and accelerate along the weft insertion channel.

Region C (sections 6-8): compressed airflow along the

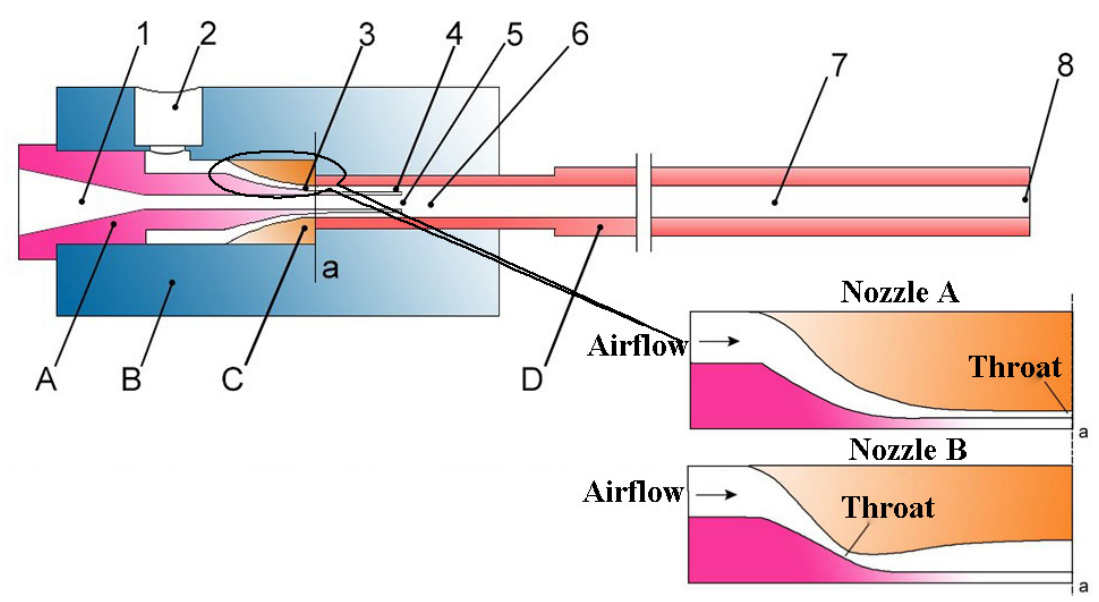

(a)

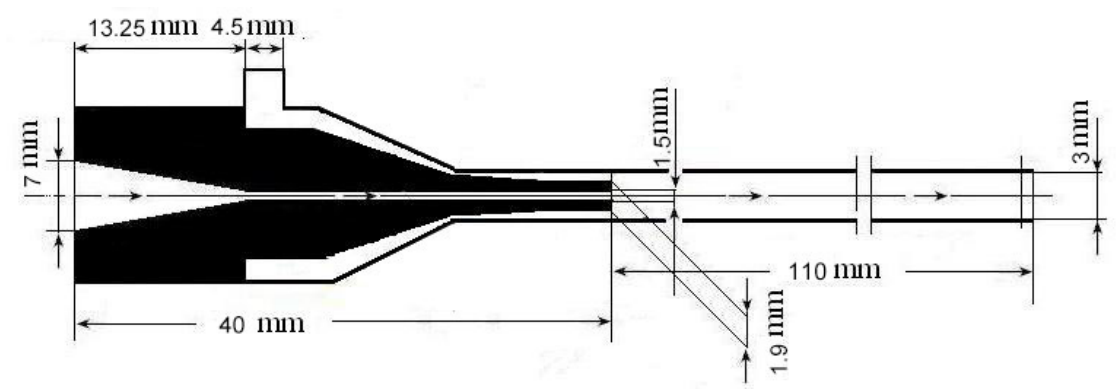

(b)

Figure 1. Structure (a) and schematic diagram (b) of the main nozzle: A, nozzle core; B, nozzle body; C, cone; D, yarn tube; 1 , weft entry; 2, air inlet; 3 and 4 , chamber throat; 5 , end of nozzle core; 6 , weft ejector region; 7 , accelerating region; 8 , air outlet 


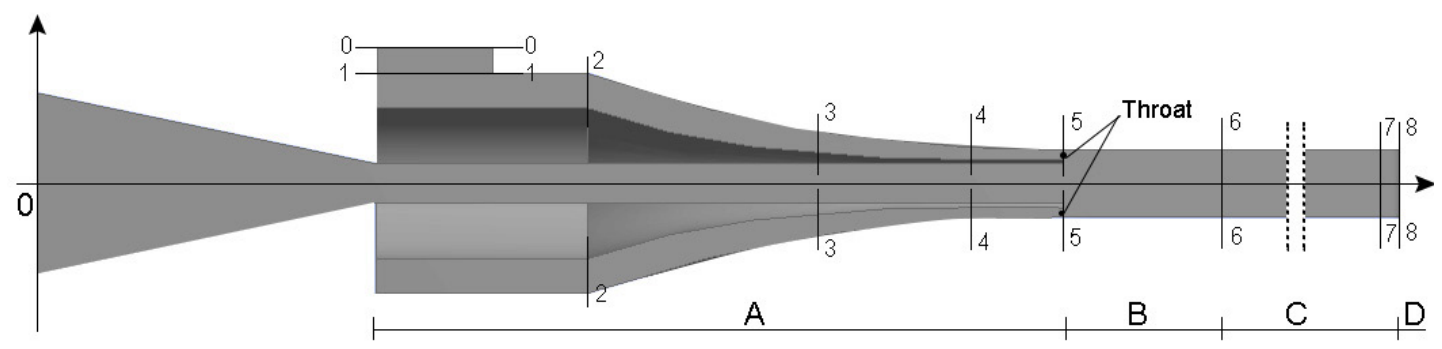

(a) Nozzle A

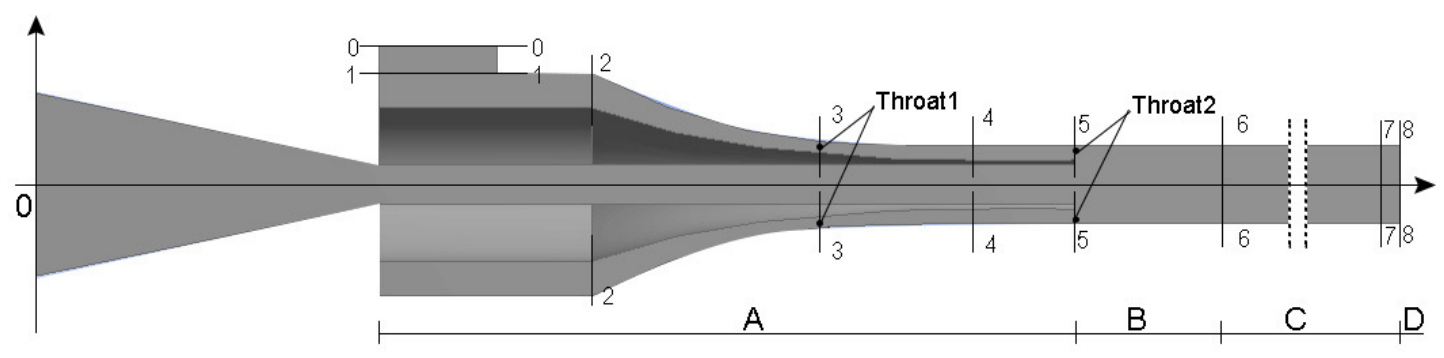

(b) Nozzle B

Figure 2. Flow field model of main nozzle

Table 1. Structure of flow field in main nozzle

\begin{tabular}{|c|c|c|c|c|c|c|c|c|c|}
\hline Zone & $\mathbf{0 \sim 1}$ & $\mathbf{1 \sim 2}$ & $\mathbf{2 \sim 3}$ & $\mathbf{3 \sim 4}$ & $\mathbf{4 \sim 5}$ & $\mathbf{5 \sim 6}$ & $\mathbf{6 \sim 7}$ & $\mathbf{7 \sim 8}$ & $\mathbf{8 \sim}$ \\
\hline Air condition in nozzle A & D & C & C & C & C & D & C & D & D \\
\hline Air condition in nozzle B & D & C & C & D & C & D & C & D & D \\
\hline
\end{tabular}

C, converge; D, divxerge.

acceleration tube, namely flow in a tube of constant crosssection which is called as "Fanno flow". Since the flow velocity boundary layer is getting thicker and thicker along the inner wall of the tube due to wall friction, effective cross-sectional area of the tube decreases which causes velocity increase and static pressure drop. At the end of the acceleration tube (sections 7-8), the flow diverges slightly owing to the thinner velocity boundary layer.

Region D (outlet): airflow jets from the exit of acceleration tube freely and diverges sharply until the jet flow pressure is consistent with the atmospheric pressure.

\section{Simulation method}

\subsection{Computational domains}

The computational domains were established as shown in Figure 3, including the inner flow field and the outer flow field of 20D length and 5D height ( $D$ is the diameter of the acceleration tube). Only half of the domain was simulated due to the axisymmetric structure of the main nozzle. The $x$-axis was defined along the tube length direction, and the coordinate system was established as shown in Figure 4.

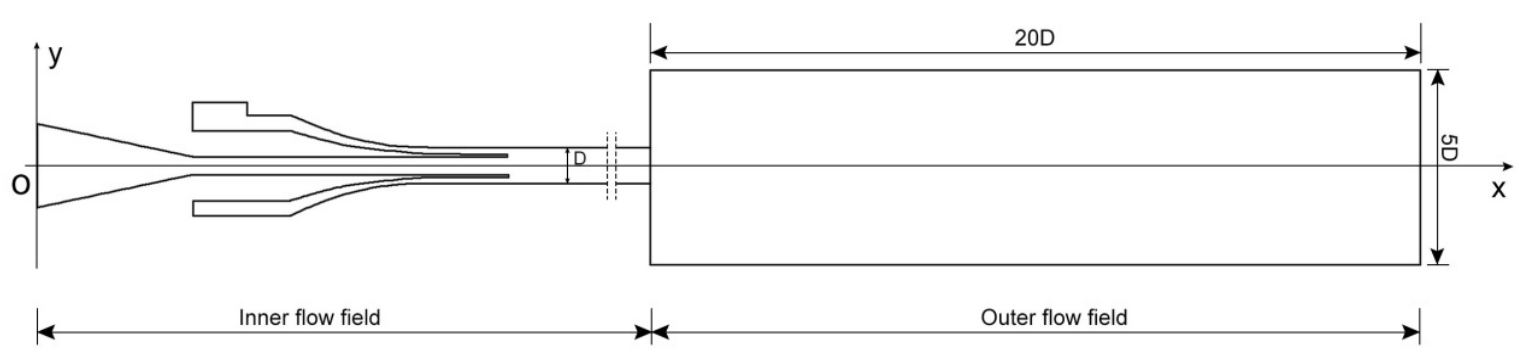

Figure 3. Computational domain of main nozzle 


\subsection{Meshing and boundary conditions}

An unstructured tetrahedral grid system of 122,225 nodes was used according to the structural characteristics of the flow field of the main nozzle as shown in Figure 4. Adiabatic no-slip wall condition and a five-layer inflation were applied to the wall. The skewness for this mesh was set as 0.6 for an improvement in mesh quality. Boundary conditions were set as follows: pressure inlet was set as pressure inlet 1 under pressure varying from $0.2 \mathrm{MPa}$ to $0.6 \mathrm{MPa}$; weft inlet was set as pressure inlet 2 under $101,325 \mathrm{~Pa}$; outlet was set as pressure outlet under 101,325 $\mathrm{Pa}$.

\subsection{Solved model and parameter setting}

The principle of weft insertion is to take advantage of air compressibility, which can lead to a high velocity of airflow and take the yarn through the shuttle. Through the injection of both main nozzle and relay nozzles make intermittent injections, based on the previous studies, the airflow tends to be steady after a period of time $[1,2]$. Besides, the air average velocity in profiled reeds can reach $80-100 \mathrm{~m} / \mathrm{s}$ [19] and a relative high Reynolds number (106-108). Therefore, the compressibility of fluid was considered and Navier-Stokes equations and $k-e$ turbulence model were used in this study. Steady simulations were performed in coupled solver based on pressure. For turbulence model, we chose standard $k-e$ as it is a model for higher Reynolds number. Total temperature was $300 \mathrm{~K}$. Airflow was assumed to be ideal gas. Turbulent intensity and turbulent viscosity ratio were set at $5 \%$ and $10 \%$, respectively.

\subsection{Experimental method}

To prove the reliability of the simulation results, the main nozzle jet flow characteristics were tested and static pressures were collected during the experiment. The sensor selected in this experiment was assembly of Pitot tube and differential pressure transmitter. Pitot was convenient, inexpensive, and had little interference with the flow field of the main nozzle. Total pressure probes and static pressure probes were placed together to measure the total pressure and static pressure at the same time. The flow velocity at the point where the probe was can be got according to the Bernoulli equation. Probes with smaller diameter were recommended to reduce interference with the flow field. A Pitot tube with a diameter of $1.6 \mathrm{~mm}$ and a differential pressure transmitter with a range of $200 \mathrm{KPa}$ were used in this experiment.

Twelve measuring holes were drilled with a diameter of $0.8 \mathrm{~mm}$ to measure the static pressure of the inner flow field, and five points were measured in the outer flow field of commonly used main nozzle, as shown in Figure 5.

Figure 6 shows the comparison of computational results and experimental results. The computational results have shown qualitative as well as quantitative agreements with the experimental results. The results were compared under different pressure conditions, ranging from $0.2 \mathrm{MPa}$ to $0.6 \mathrm{MPa}$, with an increment of $0.1 \mathrm{MPa}$. The detailed comparison on the average relative errors between the experiments and simulation is listed in Table 2. The results showed that the maximum relative error

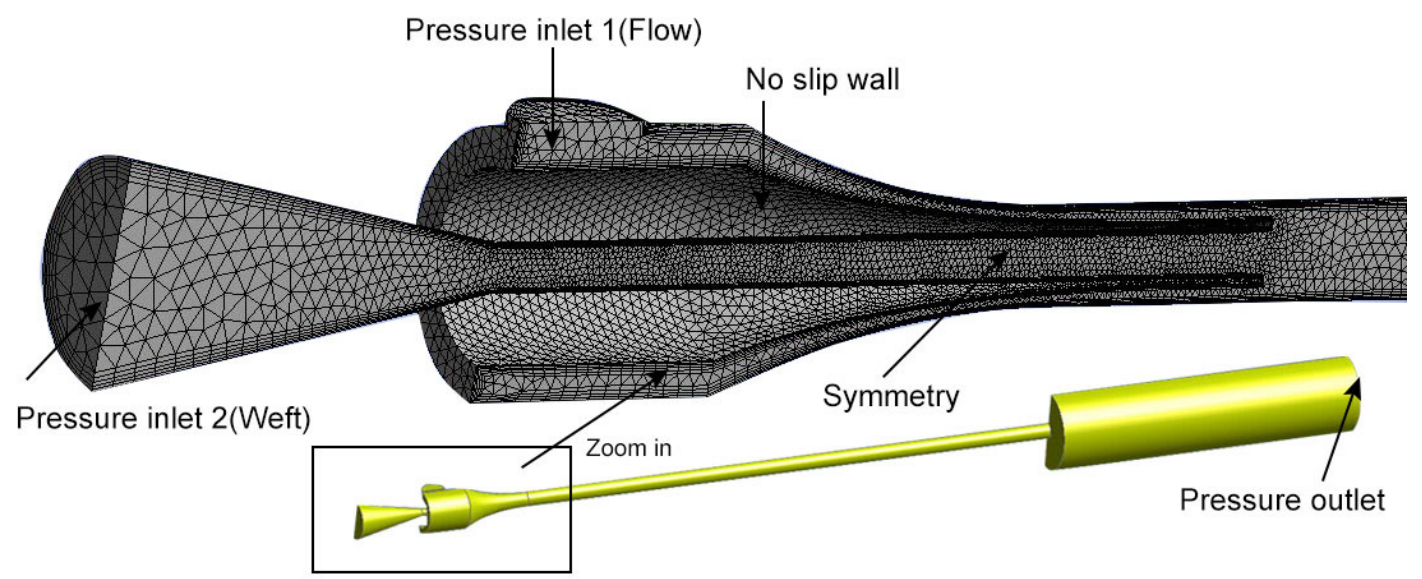

Figure 4. Main nozzle meshing model and boundary conditions

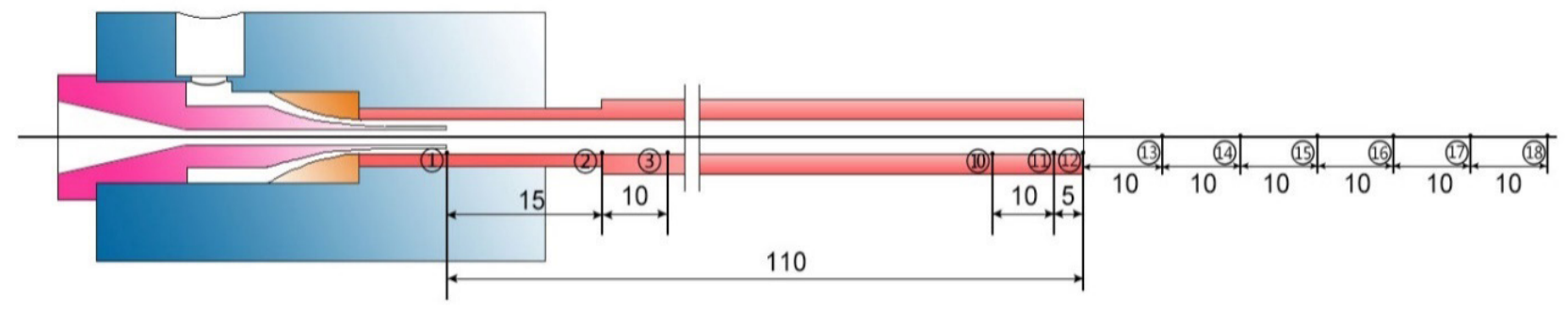

Figure 5. Positions of measurement in commonly used main nozzle 

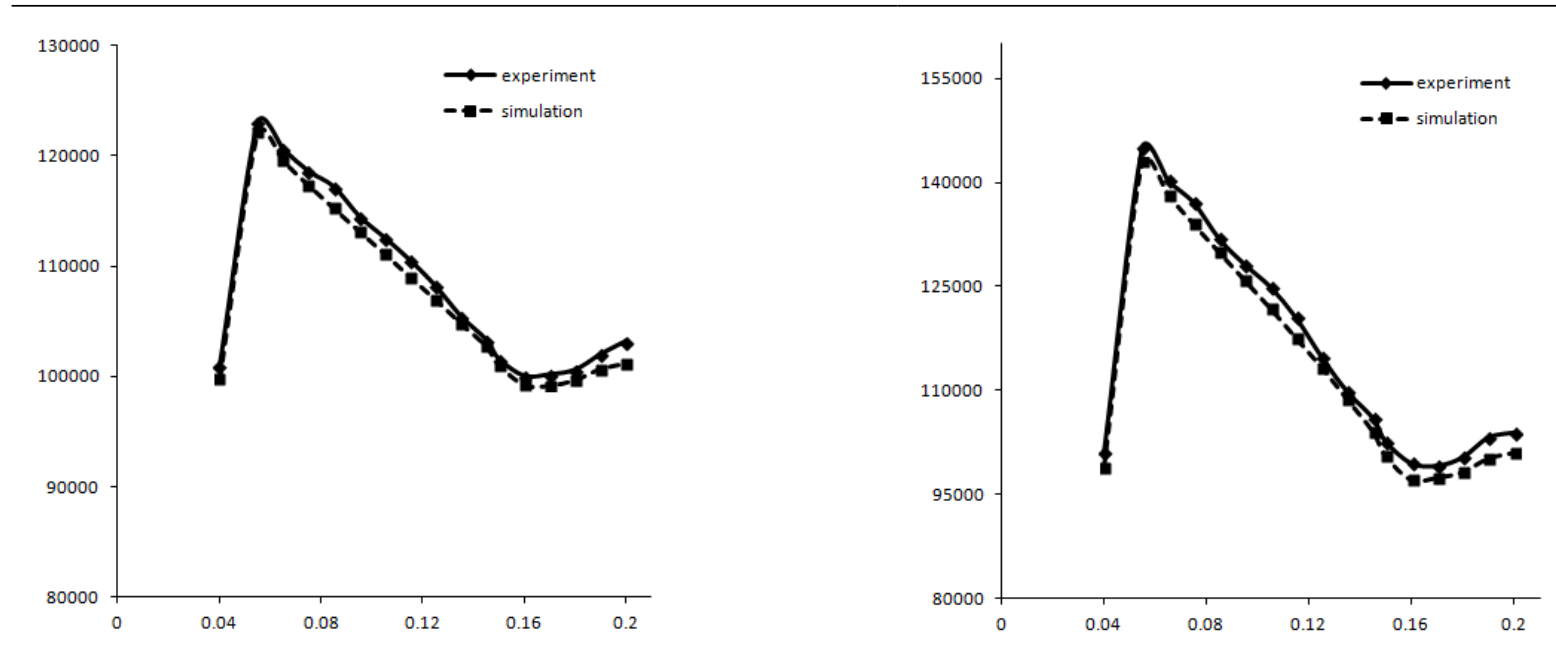

\section{(a) $0.2 \mathrm{MPa}$}

(b) $0.3 \mathrm{MPa}$
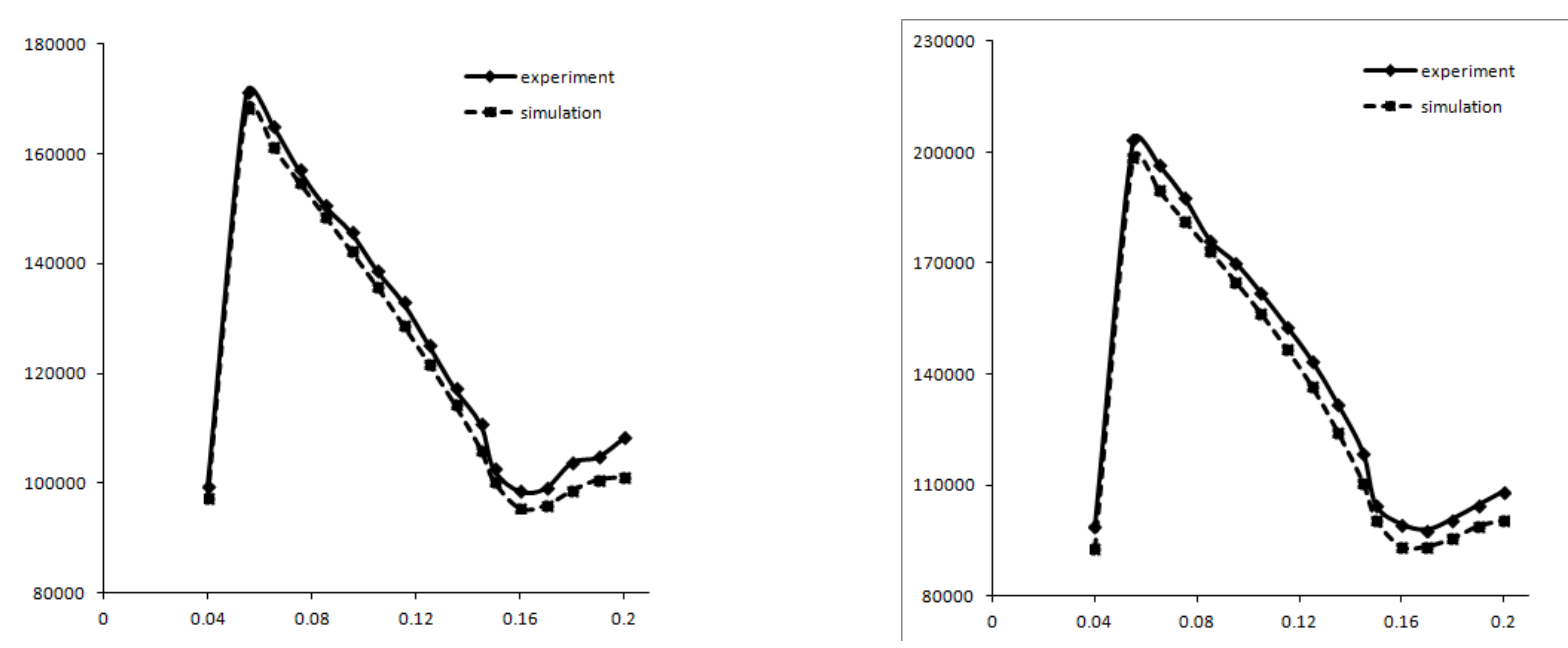

(c) $0.4 \mathrm{MPa}$

(d) $0.5 \mathrm{MPa}$

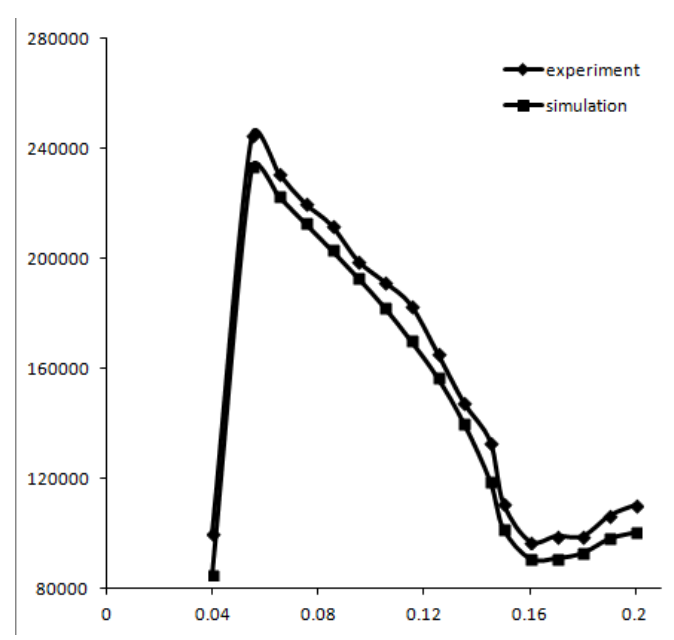

(e) $0.6 \mathrm{MPa}$

Figure 6. Comparison of measured and computational results of commonly used main nozzle

Table 2. Detailed comparison between the experiments and simulation

\begin{tabular}{|c|c|c|c|c|c|}
\hline Pressure (MPa) & $\mathbf{0 . 2}$ & $\mathbf{0 . 3}$ & $\mathbf{0 . 4}$ & $\mathbf{0 . 5}$ & $\mathbf{0 . 6}$ \\
\hline Relative error & $1.00 \%$ & $1.98 \%$ & $2.99 \%$ & $4.66 \%$ & $6.64 \%$ \\
\hline$P$-value & 0.00011 & $9.25^{\prime} 10^{-11}$ & $2.24^{\prime} 10^{-9}$ & $1.56^{\prime} 10^{-11}$ & $2.16^{\prime} 10^{-11}$ \\
\hline
\end{tabular}


was $6.64 \%$. In addition, the relative error increases with the provided pressure. Further paired-samples $t$-test was used for each pressure condition, assuming that each pilot tube point was a sample. All the results showed that $P$-value under each pressure is smaller than 0.05 , which means that the simulation can be taken as the creditability.

\section{Results and discussion}

\subsection{Velocity distribution}

For nozzle A, its Mach number curves under different supply pressures varying from $0.2 \mathrm{MPa}$ to $0.6 \mathrm{MPa}$ were drawn as shown in Figure 7(a). Airflow was compressed, accelerated sharply in region $A$, and reached its highest value in throat. $A$ sudden velocity fall occurred after flow passed through throat due to the sharp rise of airflow channel cross-sectional area. Airflow then flowed into acceleration tube and accelerated smoothly. Airflow velocity diverged slightly near the exit of

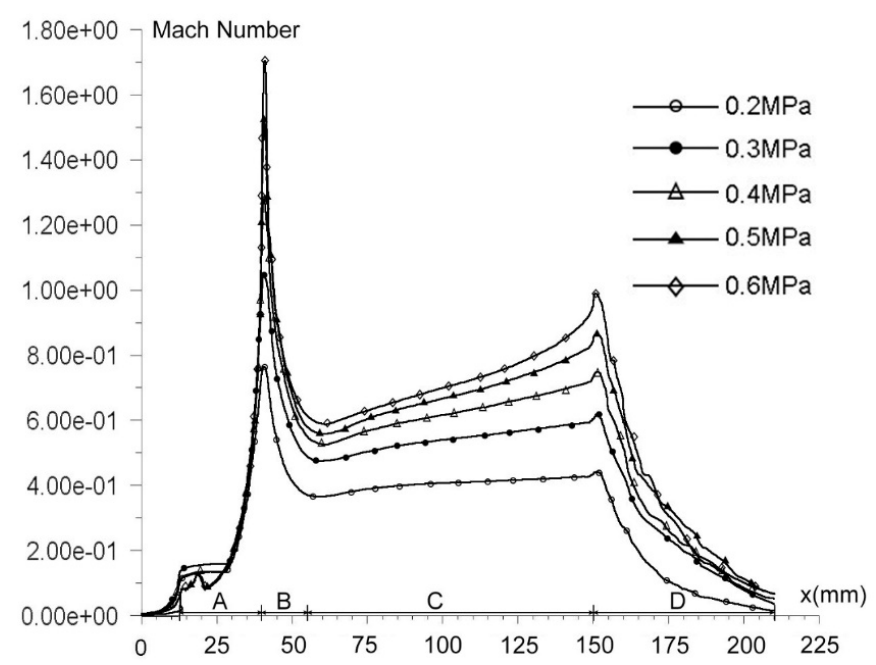

(a) Nozzle A

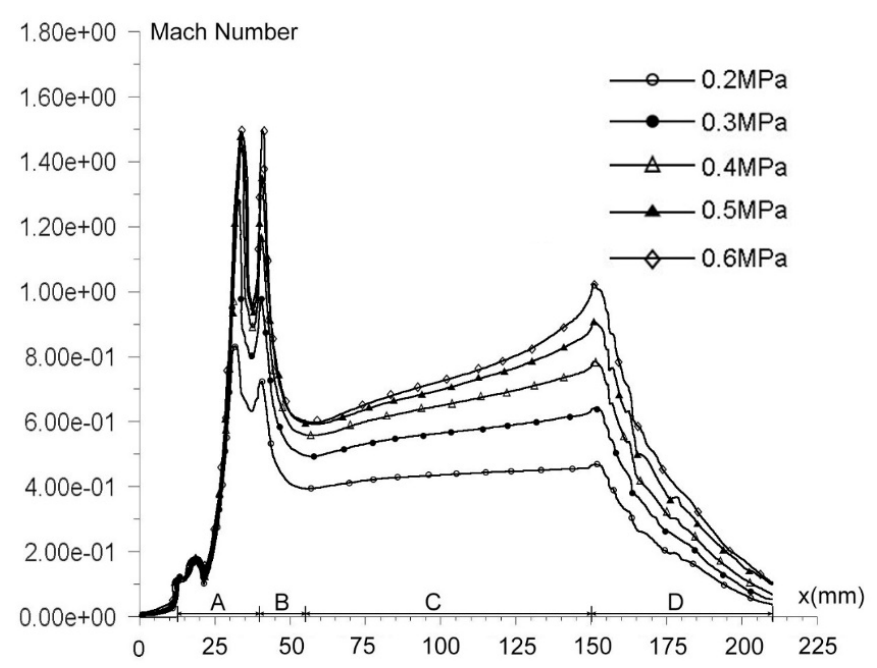

(b) Nozzle B

Figure 7. (a) Distribution of Mach numbers along $x$-axis in nozzle A; (b) distribution of Mach numbers along $x$-axis in nozzle $B$ acceleration tube due to the thinner velocity boundary layer and then decayed to zero after free injection into atmosphere. The maximum velocities in throat were $0.74 \mathrm{M}$ and $0.97 \mathrm{M}$, respectively, under $0.2 \mathrm{MPa}$ and $0.3 \mathrm{MPa}$ supply pressure, and the airflow in throat was subsonic flow. Supersonic flow occurred in throat when the supply pressure was added to $0.4 \mathrm{MPa}$. The maximum velocities in throat were $1.14 \mathrm{M}, 1.28 \mathrm{M}$, and $1.38 \mathrm{M}$, respectively, under $0.4 \mathrm{MPa}, 0.5 \mathrm{MPa}$, and 0.6 MPa supply pressure, and the airflow in throat was supersonic flow. An overall velocity increasingly took place in regions $B, C$, and $D$. The biggest increase in airflow velocity occurred when the supply pressure was increased from $0.2 \mathrm{MPa}$ to $0.3 \mathrm{MPa}$. When the supply pressure exceeded $0.3 \mathrm{MPa}$, the growth rate of velocity became slow with increasing supply pressure. The airflow velocity in acceleration tube was the most sensitive to changes in supply pressure. When the supply pressure was increased from $0.2 \mathrm{MPa}$ to $0.6 \mathrm{MPa}$, the growth rates of airflow were $33.37 \%, 49.27 \%, 64.98 \%, 78.82 \%$, and $89.21 \%$, respectively.

For nozzle $B$, its Mach number curves under different supply pressures varying from $0.2 \mathrm{MPa}$ to $0.6 \mathrm{MPa}$ were drawn as shown in Figure 7(b). There were two peaks in Mach number curves of nozzle B as they had a two-throat structure. Two throats made airflow in region $A$ one more converge-diverge process in region $B$ and improved injection capacity of nozzle $B$.

\subsection{Injection capacity of new main nozzle}

The quality of injection capacity which determines the performance of main nozzle had two evaluation indicators: airflow velocity at the exit of acceleration tube and airflow core length. Comparison of velocity at the exit of acceleration tube in nozzle $A$ and nozzle $B$ is summarized in Table 3. As the supply pressure increased, airflow velocity at the exit of acceleration tube increased, but the growth rate of velocity gradually decreased. Velocity at the exit of acceleration tube increased about $10 \mathrm{~m} / \mathrm{s}$ in nozzle $B$ when it is compared with nozzle $A$.

Comparison of airflow core length between nozzle A and nozzle $B$ under different supply pressures is shown in Figure 8. The longer the airflow jet core length was, the stronger the ability of

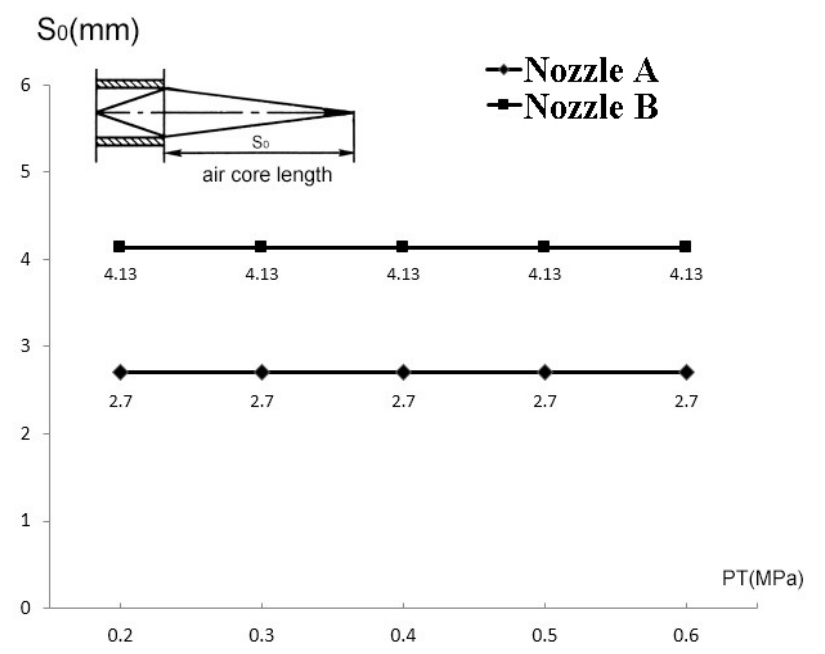

Figure 8. Comparison of airflow core length between nozzle $A$ and nozzle B 
Table 3. Comparison of velocity at the exit of acceleration tube in nozzle A and nozzle B

\begin{tabular}{|c|c|c|c|c|c|}
\hline & \multicolumn{2}{|c|}{ Nozzle A } & \multicolumn{2}{|c|}{ Nozzle B } & \multirow[t]{2}{*}{ NTC $(\mathrm{m} / \mathrm{s})$} \\
\hline & VEA $(\mathrm{m} / \mathrm{s})$ & GT (\%) & $\operatorname{VEA}(\mathrm{m} / \mathrm{s})$ & GT (\%) & \\
\hline $0.2 \mathrm{MPa}$ & 148.11 & - & 158.20 & - & 10.09 \\
\hline $0.3 \mathrm{MPa}$ & 202.80 & 36.93 & 211.97 & 33.99 & 9.17 \\
\hline $0.4 \mathrm{MPa}$ & 243.01 & 19.83 & 252.76 & 19.24 & 9.75 \\
\hline $0.5 \mathrm{MPa}$ & 274.17 & 12.82 & 287.26 & 13.65 & 13.09 \\
\hline $0.6 \mathrm{MPa}$ & 304.05 & 10.90 & 316.18 & 10.07 & 12.13 \\
\hline
\end{tabular}

GT, velocity growth rate under different supply pressures; NTC, velocity increase in nozzle B than nozzle A; VEA, velocity at the exit of acceleration tube

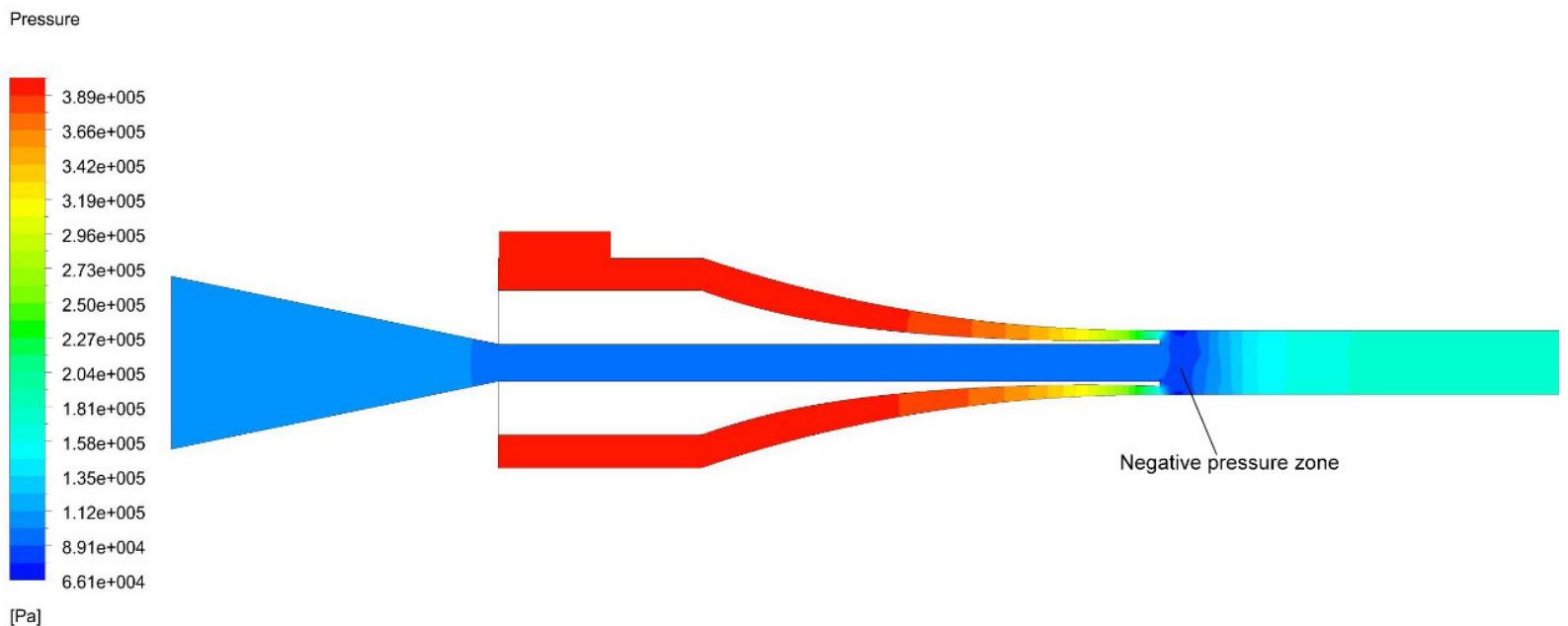

(a) Nozzle A

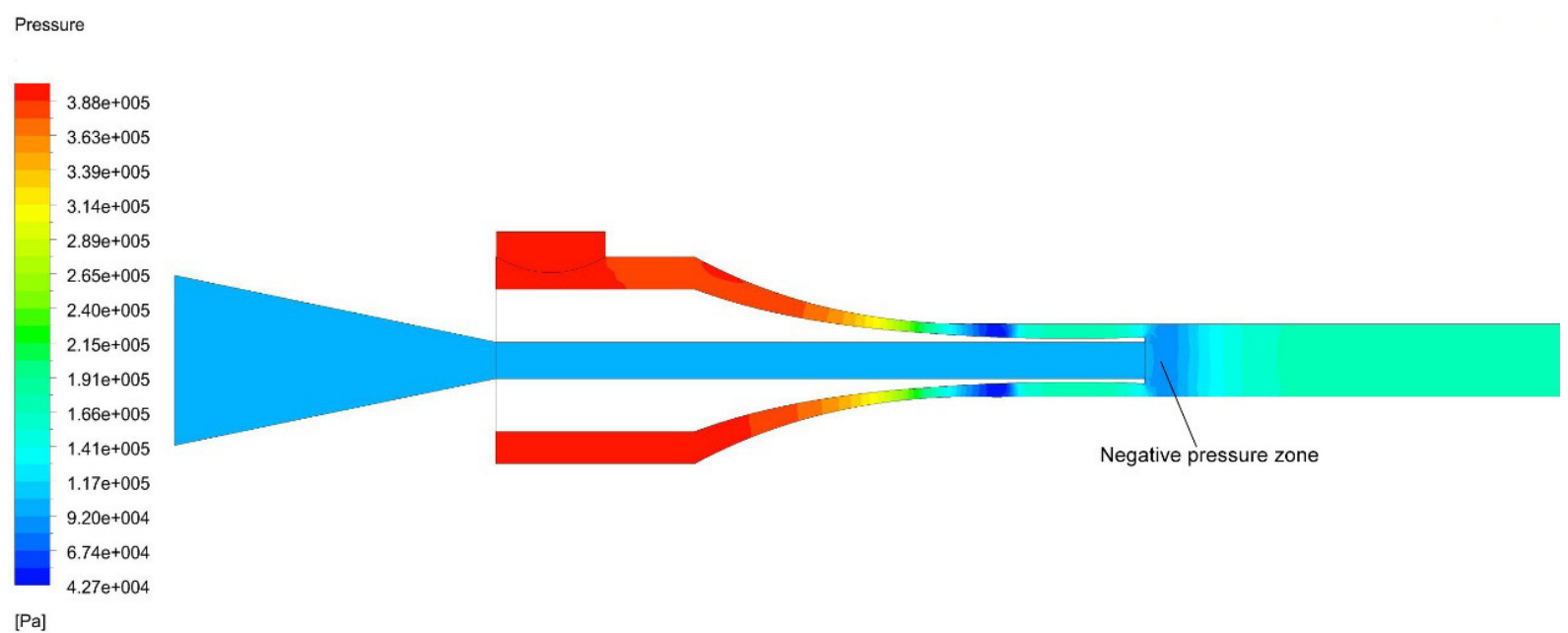

(b) Nozzle B

Figure 9. Pressure contour in symmetry

main nozzle to maintain its exit velocity. As can be seen from the diagram, an increase in supply pressure had no effect on the jet core length. Airflow jet core length depended on the nozzle structure instead of supply pressure. The airflow core length of nozzle B with a value of $4.13 \mathrm{~mm}$ was $35 \%$ higher than that of nozzle A with a value of $2.70 \mathrm{~mm}$.

\subsection{Backflow phenomenon}

A negative pressure zone (where the pressure was less than the standard atmospheric pressure) appeared in weft insertion zone affected by the high-speed velocity, as shown in Figure 9. On the one hand, the negative pressure was useful for sucking 
weft yarns; on the other hand, it also brought about backflow phenomenon. Backflow was the interference flow compared with normal airflow. Backflow would waste the energy, reduce the efficiency, and increase the gas consumption. The flow rate decayed to zero within the backflow zone and reverse flow generated. This backflow would disturb the acceleration of weft yarns.

Many studies had observed backflow phenomenon in the weft insertion region, but did not do an in-depth analysis. Backflow phenomenon was analyzed in detail, and negative pressure zone length and negative pressure value (the difference between minimum pressure in negative pressure zone and standard atmospheric pressure) were proposed to measure backflow phenomenon in this paper. The negative pressure value affected the strength of backflow phenomenon. Bigger negative pressure value indicated stronger backflow phenomenon. Longer negative pressure zone length indicated greater interference with the acceleration of weft yarns.

The velocity vector and streamline in the symmetry of flow field of main nozzle are shown in Figure 10, which clearly demonstrated the backflow phenomenon in region $B$. Nozzle $B$ alleviated the backflow phenomenon effectively compared with nozzle $A$ and helped ease the interference with the acceleration of weft yarns.

Negative pressure value and negative pressure zone length were used to evaluate the strength of backflow phenomenon, as shown in Figures 11 and 12. Smaller negative pressure value and shorter negative pressure zone length meant a weaker backflow phenomenon. Nozzle B had a shorter negative pressure zone length than nozzle $A$. For nozzle $A$, the negative pressure zone length was $1.76 \mathrm{~mm}$ and did not change when pressure increased and when supply pressure was $<0.6 \mathrm{MPa}$. When supply pressure was added to $0.6 \mathrm{MPa}$, negative pressure zone length decreased to $1.45 \mathrm{~mm}$. For nozzle $B$, the negative pressure zone length was $1.59 \mathrm{~mm}$ and did not change when pressure increased and when supply pressure was $<0.5 \mathrm{MPa}$. When supply pressure was added to $0.5 \mathrm{MPa}$, negative pressure zone length decreased with the increase in supply pressure. However, the negative pressure value increased with supply pressure. Nozzle B had a smaller negative pressure value than nozzle $A$. In conclusion, the backflow phenomenon was significantly reduced in nozzle $B$ compared with nozzle A.

\subsection{Drag force evaluation}

The air drag force acting on weft yarns which accelerated it derived from the difference between air velocity and weft velocity. To evaluate the airflow weft insertion performance in the new nozzle, air drag forces in nozzle $A$ and new main nozzle were calculated based on the previous work by Lu et al. [20]. The velocity of weft yarn was supposed to be zero, namely one end of weft yarn was fixed. The results are shown in Figure 13. As can be seen, air drag force increased with the increase in supply pressure. Airflow in nozzle B can produce much more air

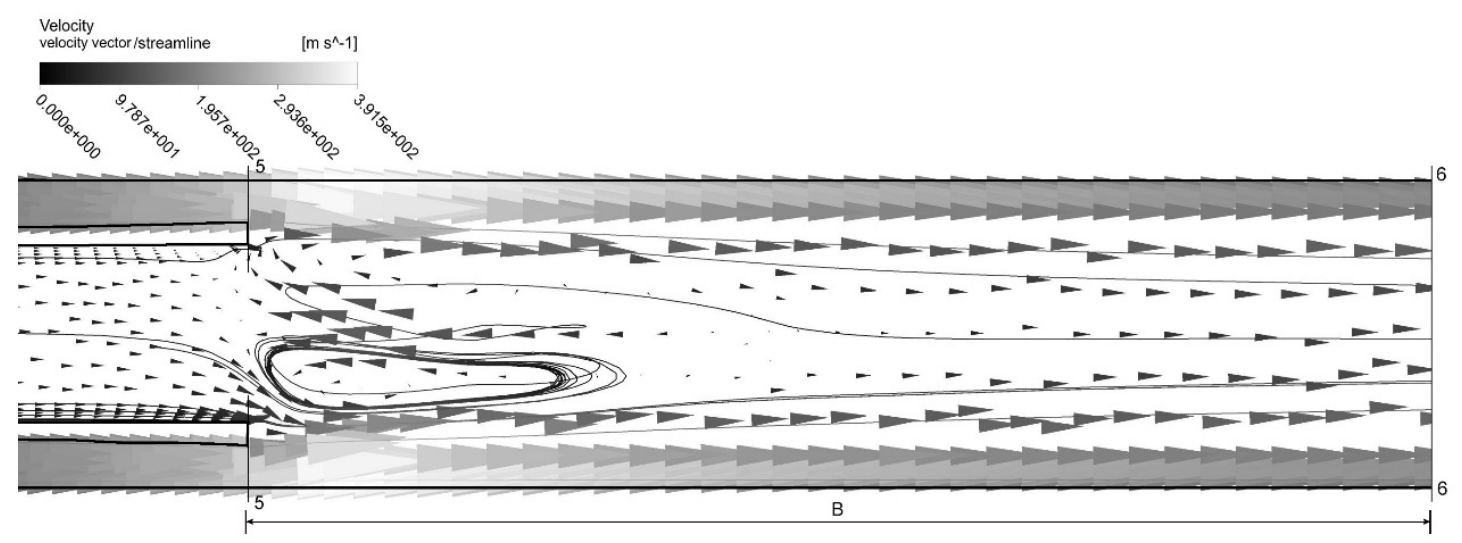

(a) Nozzle A

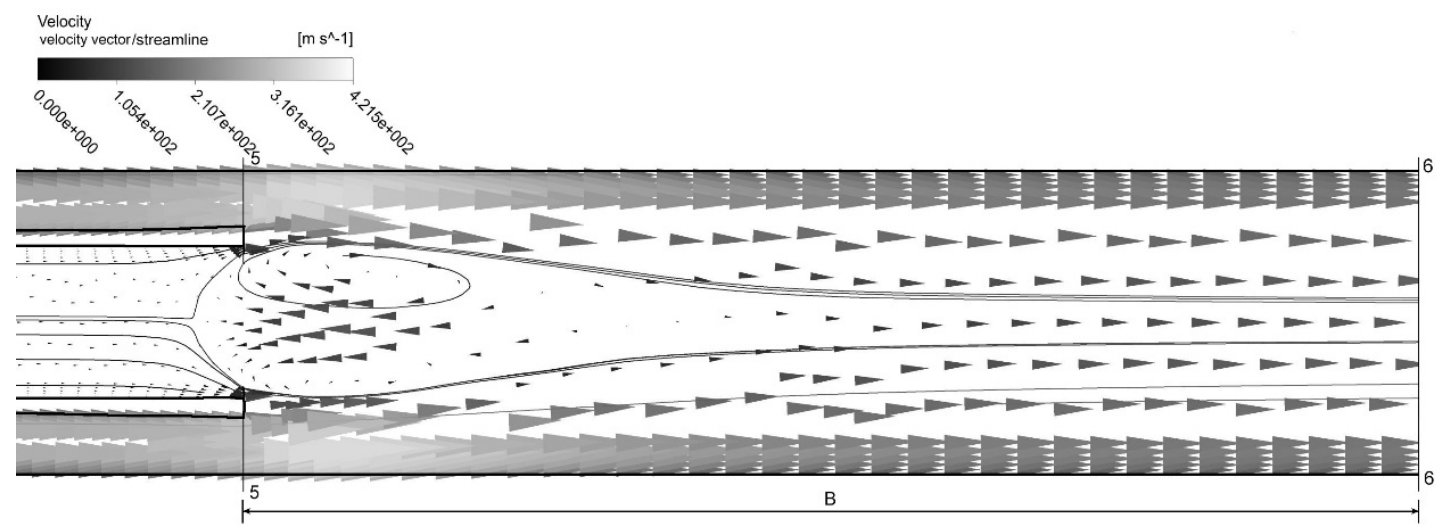

(b) Nozzle B

Figure 10. Velocity vector and streamline in region $B$ 


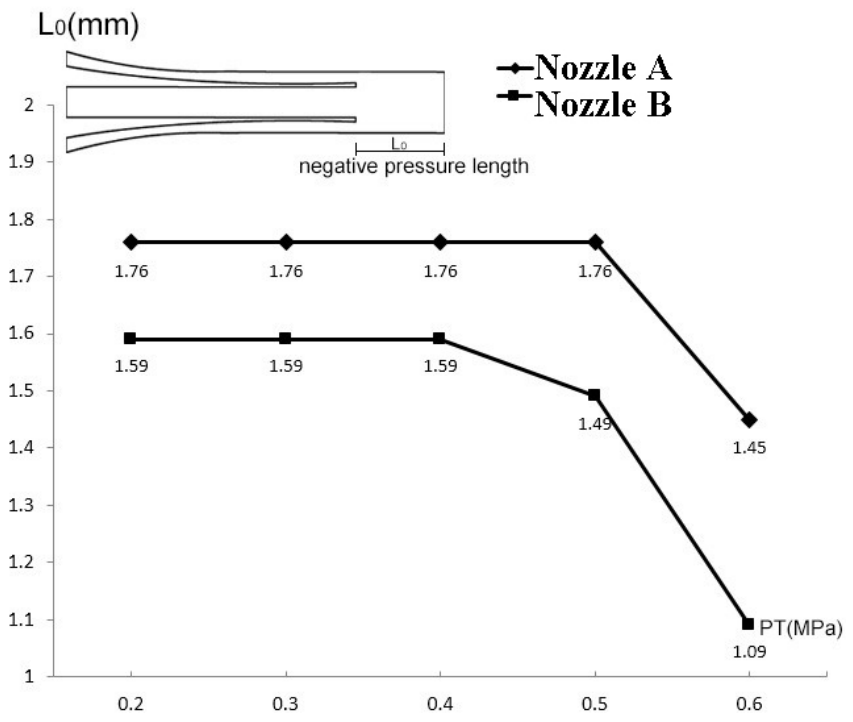

Figure 11. Comparison of negative pressure zone length between nozzle $A$ and nozzle $B$

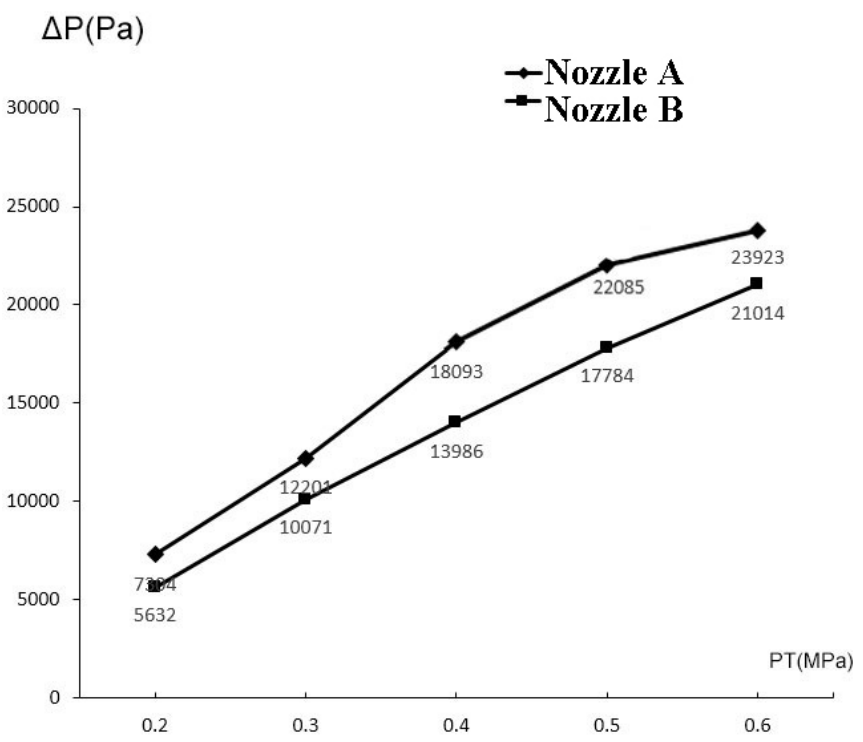

Figure 12. Comparison of negative pressure value between nozzle $A$ and nozzle B

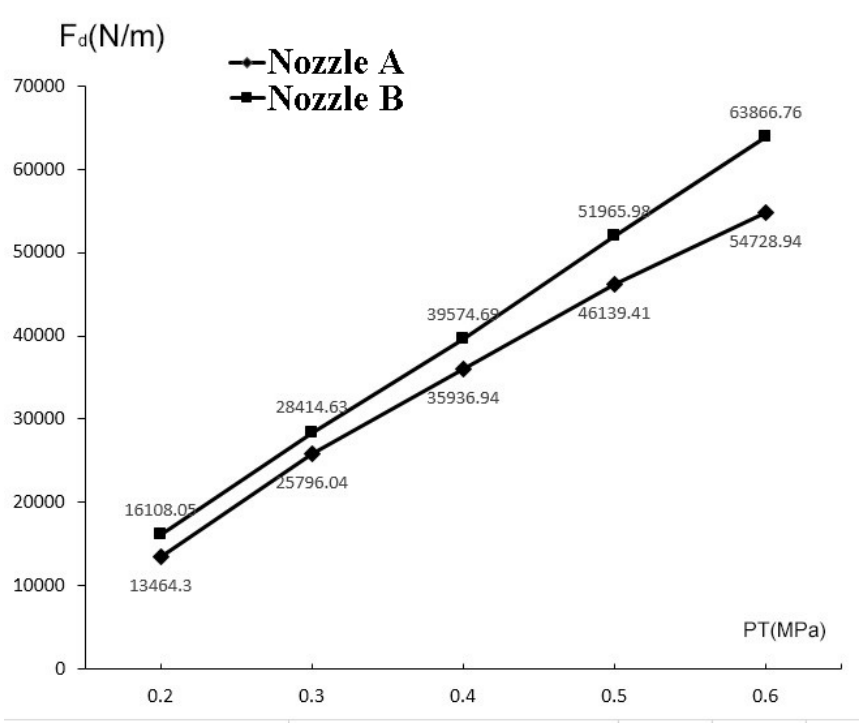

Figure 13. Comparison of air drag force between nozzle $A$ and nozzle drag force than airflow in nozzle A, which meant nozzle $B$ had stronger weft insertion ability than nozzle $A$. The growth rate of air drag force slowed down with the increase in supply pressure. Increasing the same amount of supply pressure, air drag force in nozzle B grew faster than air drag force in nozzle A.

\section{CONCLUSIONS}

In this paper, a new main nozzle structure with two throats is designed to improve airflow injection capacity of main nozzle and decrease backflow phenomenon in weft injection region. Negative pressure value and negative pressure zone length are first proposed evaluating the strength of backflow phenomenon. Experiments have been conducted to verify the simulation results. Simulation results are given in the following paragraphs.

First, there are two peaks in Mach number curves of the new main nozzle as the new nozzle has two throat structures. Two throats make airflow in region $\mathrm{A}$ one more converge-diverge process and improve injection capacity of the new main nozzle.

Second, as the supply pressure increases, airflow velocity at the exit of acceleration tube increases, but the growth rate of velocity gradually decreases. Velocity at the exit of acceleration tube increases about $10 \mathrm{~m} / \mathrm{s}$ in the new main nozzle compared with nozzle A. An increase in supply pressure has no effect on the airflow core length. Airflow core length depends on the nozzle structure regardless of supply pressure. The airflow core length of new main nozzle is $35 \%$ higher than that of nozzle $A$.

Third, the new main nozzle alleviates the backflow phenomenon effectively compared with nozzle A. The new main nozzle has a shorter negative pressure zone length and a smaller negative pressure value.

Forth, airflow in the new main nozzle can produce much more air drag force than airflow in nozzle $A$, which means that the new main nozzle has stronger weft insertion ability than nozzle $A$.

\section{ACKNOWLEDGEMENT}

This work was supported by the Fundamental Research Funds for the Central Universities (grant number 2232018D3-12), the Fundamental Research Funds for the Central University (grant number CUSF-DH-D-2018030), National Science and Technology Major Project (grant number 2017YFB0309100), and the Applied Basic Research Programs of "Glory of Textiles" (grant number J201807).

\section{References}

[1] Adanur, S., Mohamed, M. H. (1991). Analysis of airflow in air-jet filling insertion. Textile Research Journal, 61(5), 253-258.

[2] Yan, Y., Zhang, W., Chen, Y. (1995). Intermittence of air-jet influence on air-jet weft insertion. Journal of China Textile University, 21(4), 96-100. 
[3] Mohamed, M. H., Salama, M. (1986). Mechanics of a single nozzle air-jet filling insertion system part I: nozzle design and performance. Textile Research Journal, 56(11), 683-690.

[4] Zhu, Z. (1994). Weft features of airflow from main nozzle (in Chinese). Cotton Textile Technology, 22(8), 4-9.

[5] Ishida, M., Okajima, A. (1994). Flow characteristics of the main nozzle in an air-jet loom part I: measuring flow in the main nozzle. Textile Research Journal, 64(1), 10-20.

[6] Ishida, M., Okajima, A. (1994). Flow characteristics of the main nozzle in an air-jet loom part II: measuring high speed jet flows from the main nozzle and weft drag forces. Textile Research Journal, 64(2), 88-100.

[7] Chen, Y. W., Shen, L., Lin, L. (2007). Test and analysis of weft force for air-jet loom's main nozzle. Journal of Zhejiang Sci-tech University, 24(3), 238-242.

[8] Oh, T. H., Kim, S. D., Song, D. J. (2001). A numerical analysis of transonic/supersonic flows in the axisymmetric main nozzle of an air-jet loom. Textile Research Journal, 71(9), 783-790.

[9] Kim, H. D., Lim, C. M., Lee, H. J., Chun, D. H. (2007). A study of the gas flow through air jet loom. Journal of Thermal Science, 16(2), 159-163.

[10] Kim, S. D., Seo, J. I., Song, D. J. (2007). A computational analysis of unsteady transonic/supersonic flows over backward facing step in air jet nozzle. Journal of Mechanical Science and Technology, 21(2), 336-347.

[11] Guo, J., Feng, Z., Zeng, T. (2009). 3D analyses on the inner flow field of the main nozzle in air-jet looms based on fluent. Journal of Suzhou University (Engineering Science Edition), 29(2), 38-42.

[12] Yuan, D., Yuan, Y., Feng, Z. (2010). Analyses on the flow field of the main nozzle in an air-jet loom based on fluent. Journal of Suzhou University (Engineering Science Edition), 27(2), 14-17.
[13] Zhang, K., Feng, Z., Wang, S. (2010). Analysis of weft insertion flow of the main nozzle in an air jet loom base on CFD. Journal of Suzhou University (Engineering Science Edition), 30(4), 20-23.

[14] Liu, D. D., Feng, Z. H., Tan, B. H., Tan, Y. P. (2012). Numerical simulation and analysis for the flow field of the main nozzle in an air-jet loom based on fluent. Applied Mechanics and Materials, 105, 172-175.

[15] Dong, T., Feng, Z., Wang, W., Chen, L., Liu, S. (2014). Numerical simulation and experimental verification of weft insertion flow field of main nozzle in air-jet loom. Journal of Textile Research, 35(5), 126-131.

[16]Xue, W., Wei, M., Chen, G., et al. (2010). Numerical simulation of flow field in main nozzle of air jet loom. Journal of Textile Research, 31(4), 124-127.

[17] Wu, C., Chen, G., Xue, W. (2010). Numerical simulation of a three-dimensional flow field in main-nozzle of air-jet loom based on fluent. Journal of Donghua University (Natural Science), 36(1), 66-69.

[18] Chen, L., Feng, Z., Dong, T., et al. (2015). Numerical simulation of the internal flow field of a new main nozzle in an air-jet loom based on fluent. Textile Research Journal, 85(15), 1590-1601.

[19]Zhang, G. P., (2005). Principle of weft insertion and process. China Textile \& Apparel Press.

[20] Lu, X. F., Feng, Z. H., Sun, Z. K., Lv, F. (2011). Calculation and analysis of weft insertion force for air-jet loom's main nozzle based on fluent. Journal of Textile Research, 32(9), 125-129. 